\title{
The effect of co-contraction exercises of abdominal bracing combined with ankle dorsiflexion on abdominal muscle thickness and strength in patients with chronic low back pain
}

\author{
Wenlan Chai ${ }^{a}$, So Hee Lee ${ }^{b}$, Yu Hyung Park ${ }^{c}$ \\ aWaverly Physiotherapy Clinic, Glenwaverly, Australia \\ ${ }^{b}$ Department of Physical Therapy, Spine Health Care Center, Wooridul Spine Hospital, Seoul, Republic of Korea \\ ${ }^{\mathrm{C}}$ Department of Physical Therapy, Rehabilitation Medicine Center, Bobath Memorial Hospital, Seongnam, Republic of Korea
}

Objective: The purpose of this study was to determine the effect of the abdominal bracing (AB) and abdominal bracing combined with ankle dorsiflexion (ABDF) on abdominal muscle thickness and strength in patients with chronic low back pain (LBP).

Design: Two group pretest posttest design.

Methods: Sixteen subjects were divided randomly into two group: ABDF group ( $n=8)$, and alone AB group ( $n=8)$. The ABDF group practiced $\mathrm{AB}$ exercise with additional ankle dorsiflexion. AB group practiced only $\mathrm{AB}$ exercises. Subjects in both groups received $\mathrm{ABDF}$ exercise and $\mathrm{AB}$ exercise for 40 min per day, three days per week during a period of three weeks, respectively. All the subjects were evaluated for abdominal muscle thickness and strength before and after intervention using ultrasonography and MedX machine.

Results: The external oblique (EO), internal oblique, transverse abdominis ( $\operatorname{Tr} \mathrm{A}$ ) muscle thickness and the strength produced at $48^{\circ}, 60^{\circ}, 72^{\circ}$ showed a significant increase in the ABDF group after intervention, with a more significant improvement in EO and TrA muscle thickness in the ABDF group compared with the AB group $(p<0.05)$. Also, the strength at $48^{\circ}$ strength showed a significant improvement in the ABDF group than the $\mathrm{AB}$ group $(p<0.05)$.

Conclusions: The study results showed that abdominal muscle contraction exercises with AD in patients with LBP had an influence on abdominal muscle thickness and strength. Therefore, these findings suggest that ABDF may be useful approach for enhancement of abdominal muscle thickness and strength in patients with chronic low back pain.

Key Words: Abdominal muscle, Low back pain, Ultrasonography

\section{Introduction}

Low back pain (LBP) is defined that as pain, tension or tonus of muscle from lower ribs through the hip line with or without leg pain (sciatica) [1]. Approximately $10 \%-40 \%$ of acute LBP patients become chronic and most of them are classified as nonspecific. Patients who develop chronic nonspecific LBP are responsible for more than $80 \%$ of health care costs that are spent for spinal problem [2]. It has an effect on making appropriate trunk action suitable for its phys- ical and functional activities. This could have an effect on the co-activation and the changes in superficial and deep muscles of trunk [3].

Decreased deep muscle activity commonly occurs in patients with relapsed back pain [4,5]. On the other hands, superficial muscles get activated more than usual [3]. People who are at a risk for the LBP also have the changes in those muscles [6-8].

Exercises for strengthing abdominal lumbar extensors could assist in pain relief as well as performing tasks. It rep-

Received: 29 August, 2014 Revised: 30 October, 2014 Accepted: 18 November, 2014

Corresponding author: Yu Hyung Park

Department of Physical Therapy, Rehabilitation Medicine Center, Bobath Memorial Hospital, 155-7 Daewangpangyo-ro, Bundang-gu, Seongnam 463-869,

Republic of Korea

Tel: 82-31-786-3250 Fax: 82-31-786-3026 E-mail: pyh0627@hanmail.net

(c) This is an Open-Access article distributed under the terms of the Creative Commons Attribution Non-Commercial License (http://creativecommons.org/licens es/by-nc/3.0) which permits unrestricted non-commercial use, distribution, and reproduction in any medium, provided the original work is properly cited.

Copyright $\odot 2014$ Korean Academy of Physical Therapy Rehabilitation Science 
resents that LBP is related to the deep muscle dysfunction caused by the instability of hyper-mobile spine segments which is resulted from muscle control [9].

Recent studies about non-surgical treatment for LBP supports that it is a necessary to restore neuro-muscular control of the transverse abdominal muscle and minimize the use of superficial abdominal muscles during an initial stage of rehabilitation $[5,10,11]$. Selective movement in the transverse abdominal muscle that plays a major role in core stability may be helpful in treating for LBP [12]. Therefore stabilization exercise has to be applied for the treatment of dysfunction neuro-muscular control [9].

Abdominal bracing $(\mathrm{AB})$ promoted the activities of three abdominal layers; external/internal oblique (EO/IO), transverse abdominis ( $\operatorname{TrA}$ ) and rectus abdominis which stabilize lumbar spines [13]. Abdominal muscle contraction is a key to place the lumbar spines in the neutral range. Deliberate abdominal activities reinforce the stabilization process during daily activities, work activities, and even sports. Abdominal muscles activate against external forces to enhance a series of muscles surrounding lumbar spines. Stability in the lumbar spines which possibly could reduce the chances of mechanical damage, must be considered and are needed for restoring in LBP patients. That is to say, building up abdominal muscle strength in LBP patient is not an option but a must [14].

Lumbar spine stability is emphasized when the muscles are co-activated against trunk muscles $[5,15,16]$. Stability is summed up when deep muscle training on the trunk and training in the upper/lower extremities are performed at the same time [17]. TrA and IO are part of deep muscles, providing stability while the tasks are assigned [13]. Active muscle contraction in those muscles leads to protect the supine structures [18]. The pattern of muscle contraction in the patients with LBP is different from those who without LBP $[19,20]$. Previous research has demonstrated that people with back pain have neuromuscular dysfunction of the back and abdominal muscles [21]. Studies of LBP have suggested that intervention using motor control exercise can improve both objective and subjective outcomes of treatment [22].

The motor control exercise has become very popular as a clinical practice method for the treatment of nonspecific LBP. The evidence of motor control exercise is that the deep abdominal muscle wall has a key role in the dynamic control of the lumbar spine. The AB exercise using pressure biofeedback unit (PBU) is a one method of motor control exercise for treatment in LBP [23]. The PBU is a device devel- oped by physiotherapists to aid the training and measurement of abdominal muscle activity using visual biofeedback. Recent study has demonstrated that the AB exercise using PBU by useful visual biofeedback used to improve to LBP [24].

Another method to augment the abdominal muscle is in co-contraction of active ankle dorsiflexors and deep abdominal muscles. This approach was derived from the concept of irradiation in proprioceptive neuromuscular facilitation, which emphasizes the important contribution of the important contribution of the relatively stronger distal muscle group [25]. Previous studies reported that the co-contraction of the rectus femoris muscles and ankle dorsiflexors effectively augmented the activation of deep abdominal muscle [12].

Therefore, the purpose of our study was to determine the effects of the pressure biofeedback training and pressure biofeedback combined with ankle contraction on abdominal muscles thickness and strength in people with chronic LBP.

\section{Methods}

\section{Subjects}

This study used a pretest-posttest design, and the sixteen participants with symptoms of chronic nonspecific LBP were randomly recruited from an outpatient musculoskeletal physical therapy service unit within the Wooridul Spine Hospital.

General characteristics such as sex, age, height, and weight of participants were obtained from patient interview, and confirmed via review of medical records (Table 1), and also participants were determined to be in the experimental group by drawing cards inscribed from 1 to 10 . Inclusion criteria for participants were: (1) a diagnosis of nonspecific LBP of non-traumatic causes; (2) age 20-40 years; (3) LBP persisting for at least 3-month or more; ability to perform the movement of the experimental intervention. Exclusion criteria included participants who had previous abdominal wall or spinal surgery, and other neurologic conditions.

Sixteen subjects were randomly assigned to either the AB exercise group or abdominal bracing combined with ankle dorsiflexion (ABDF) group.

The study was approved by the Sahmyook University institutional review board, and all the participants provided their informed consent. 
Table 1. General characteristics of subjects

$(\mathrm{N}=16)$

\begin{tabular}{lcccc}
\hline \multicolumn{1}{c}{ Characteristic } & ABDF group $(\mathrm{n}=8)$ & AB group $(\mathrm{n}=8)$ & $X^{2} / t$ & $p$ \\
\hline Sex $($ male/female) & $3(38) / 5(62)$ & $3(38) / 5(62)$ & 1.000 & 1.000 \\
Age $(\mathrm{y})$ & $23.38(3.46)$ & $25.25(4.03)$ & 0.693 & 0.511 \\
Height $(\mathrm{cm})$ & $164.63(8.58)$ & $165.00(6.91)$ & 1.369 & 0.276 \\
Weight $(\mathrm{kg})$ & $59.38(10.27)$ & $59.28(7.13)$ & 0.520 & 0.602 \\
\hline
\end{tabular}

Values are presented as $\mathrm{n}(\%)$ or mean (SD).

ABDF: abdominal bracing combined with ankle dorsiflexion, $\mathrm{AB}$ : abdominal bracing.

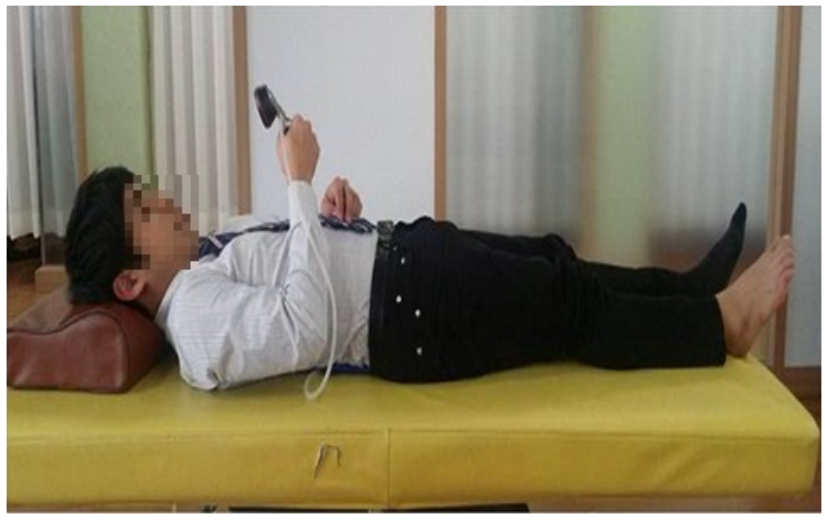

Figure 1. Abdominal muscle contraction using pressure biofeedback unit.

\section{Procedures}

All participants were previously instructed twice for test and training methods prior to test.

In the present study, the contraction method of each abdominal muscle was composed of based previous studies [25].

All participants were measured using the ultrasonography (SEQUOIA 521; Siemens Inc., Erlangen, Nürnberg, Germany, 2002) and the MedX Medical Lumbar machine (MedX Inc., Ocala, FL, USA, 1993) in order to assess their abdominal muscle thickness and strength before and after intervention of each group. The AB group training was as follows. The contraction of abdominal muscles were controlled by a PBU, and the pressure of the biofeedback unit were used which standardized the contractile force of an abdominal muscle [26]. The biofeedback unit is a simple pressure transducer consisting of a three-chamber air-filled pressure bag, a catheter and a sphygmomanometer gauge [27]. The pressure bag is $16.7 \times 24 \mathrm{~cm}$ in size and made from inelastic material. The biofeedback unit has an excellent in inter-rater and intra-rater reliability (intraclass correlation coefficient $[\mathrm{ICC}]=0.74,0.76$, respectively) [28]. The meas-

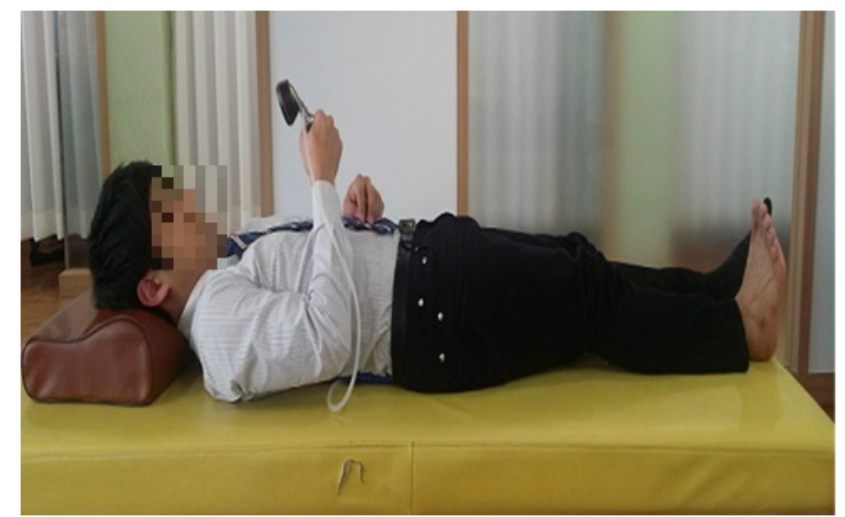

Figure 2. Abdominal muscle contraction using pressure biofeedback unit with ankle dorsiflexion.

ured value has a range from $0 \mathrm{mmHg}$ to $200 \mathrm{mmHg}$, with 2 -mmHg intervals on the scale. The pressure changes along with the postural changes were measured by the sphygmomanometer of the biofeedback unit.

Before starting the contractions, the inflatable bag from the biofeedback unit was placed under the lumbar curvature between first lumbar vertebra and second sacrum, and the bag was inflated to a pressure of $70 \mathrm{mmHg}$ with the valve closed. For abdominal contraction, all participants were instructed to produce a smooth contraction without moving the spine and pelvis, and the pressure reduction was not to exceed from 4 to $10 \mathrm{mmHg}$, and maintain these contractions for 10 seconds [29] (Figure 1). During abdominal muscle contraction, the breathing was to have normal play without a visible movement the lumbar vertebrae and pelvis, and rib [26].

The AB exercise combined ankle dorsiflexion group pulled the ankle toward the head in order to create ankle dorsiflexion during contraction of the abdominal muscle in the same manner with the AB group (Figure 2).

Each participant of both group were instructed to maintain the contraction for 10 seconds, relax for 10 seconds, were given a 1 minute rest period after performing the con- 
traction and relaxing 10 times, 1 set ( 1 session). 3 set performed overall 10-session, 1 set. This intervention method received for 40 minutes per day, three days per week during a period of three weeks, respectively [30].

\section{Clinical measures}

\section{Muscle thickness}

Ultrasonography is a reliable and valid method of assessing the structure of the functions and activities being used by physical therapists [31,32]. This technique is important to research the activity of deep muscles such as deep abdominal muscles and muscle contractions can be studied in real time $[33,34]$. During measurement with the ultrasonography, abdominal muscle thickness changes can be measured as an indicator of the abdominal muscles activity. A comparison of magnetic resonance imaging (MRI) and ultrasonography measurements showed a high correlation in one study [35], electromyography (EMG) activity of the low-intensity muscle contractions in comparison with the thickness variations were correlated $[4,7]$.

Ultrasonography as an indicator of muscle activity is a non-invasive method to measure the thickness of the muscle and is a reliable tool [36]. Diagnostic ultrasonography unit used was B-mode, 4.0 MHz. Based on that described in other studies, abdominal muscle thickness change during muscle contraction was measured [36-38].

For measurement purposes, the Convertor to measure was placed on the horizontal axis between the 12th rib and iliac crest over right anterior axillary line. The anteriolateral abdominal muscle layer was located so that it appears clearly.

Participants were trained on exactly how to produce the abdominal muscle contraction by the physical therapist during the pretest. The cursor displayed on the screen for the ultrasonography was used to measure the thickness of the muscle between the fascia band. Muscle thickness by the cursor in the still image was measured in centimeters. Converter has been placed during the examination. The abdominal muscle contraction (EO, IO, TrA) was to occur three times for analysis. All measurements were carried out by one observer to increase the intra-rater reliability [39].

The transducer head for measurement was positioned transversely $2.5 \mathrm{~cm}$ anteromedial to the midway point between the 12th rib and iliac crest. The head of the transducer was maneuvered until the sharpest images of all lateral abdominal muscles (EO, IO, TrA) had been obtained. [40].

\section{Muscle strength}

The subject seat on the MedX (MedX Inc.) with in trunk

Table 2. The changes in abdominal muscle thickness during contraction after exercise

$(\mathrm{N}=16)$

\begin{tabular}{|c|c|c|c|c|c|c|}
\hline \multirow{2}{*}{ Abdominal muscle } & \multicolumn{2}{|c|}{ ABDF group $(n=8)$} & \multicolumn{2}{|c|}{ AB group $(n=8)$} & \multirow{2}{*}{$t^{\mathrm{b}}$} & \multirow{2}{*}{$p$} \\
\hline & Pre-test & Post-test ${ }^{\mathrm{a}}$ & Pre-test & Post-test & & \\
\hline External oblique $(\mathrm{cm})$ & $0.46(0.12)$ & $0.53(0.12)^{*}$ & $0.50(0.12)$ & $0.53(0.11)$ & -2.342 & 0.031 \\
\hline Internal oblique $(\mathrm{cm})$ & $0.68(0.25)$ & $0.73(0.25)^{*}$ & $0.90(0.32)$ & $1.01(0.26)$ & 1.001 & 0.330 \\
\hline Transverse abdominis $(\mathrm{cm})$ & $0.42(0.11)$ & $0.49(0.11)^{*}$ & $0.55(0.17)$ & $0.57(0.12)$ & -2.185 & 0.042 \\
\hline
\end{tabular}

Values are presented as mean (SD).

ABDF: abdominal bracing combined with ankle dorsiflexion, AB: abdominal bracing.

${ }^{\mathrm{a}}$ Paired t-test, ${ }^{\mathrm{b}}$ Independent t-test.

${ }^{*} p<0.05$.

Table 3. The changes of abdominal muscle strength

\begin{tabular}{|c|c|c|c|c|c|c|}
\hline \multirow{2}{*}{ MedX angle } & \multicolumn{2}{|c|}{ ABDF group $(n=8)$} & \multicolumn{2}{|c|}{ AB group $(n=8)$} & \multirow{2}{*}{$t^{\mathrm{b}}$} & \multirow{2}{*}{$p$} \\
\hline & Pre-test & Post-test ${ }^{\mathrm{a}}$ & Pre-test & Pre-test & & \\
\hline $\operatorname{MedX} 48^{\circ}(\mathrm{Nm})$ & $117.65(69.39)$ & $132.51(63.70)^{*}$ & $129.39(54.16)$ & $133.71(56.83)^{*}$ & -2.575 & 0.019 \\
\hline $\operatorname{MedX} 60^{\circ}(\mathrm{Nm})$ & $129.67(70.11)$ & $153.17(57.33)^{*}$ & $153.17(57.33)$ & $157.94(57.16)$ & -1.817 & 0.086 \\
\hline $\operatorname{MedX} 72^{\circ}(\mathrm{Nm})$ & $139.55(65.58)$ & $158.91(14.42)^{*}$ & $168.40(59.14)$ & $179.70(31.79)$ & -0.730 & 0.475 \\
\hline
\end{tabular}

Values are presented as mean (SD).

ABDF: abdominal bracing combined with ankle dorsiflexion, $\mathrm{AB}$ : abdominal bracing.

${ }^{\mathrm{a}}$ Paired t-test, ${ }^{\mathrm{b}}$ Independent t-test.

${ }^{*} p<0.05$. 
in vertical upright position and about 15 degrees of femoral maintained. The upper front side of the femur by using the belt was firmly is fixed, the femoral fixation pad was firmly fixed on above the knee and infront of the femur. Such fixation of the pelvis and the femur prevents unnecessary vertical movements. In addition, the upper body movement against gravity was quantified as the value of the weight. When the test was ready to start, movement of the arm of the machine was fixed in an appropriate joint angle of the machine and it was measured using a goniometer of the machine. After subjects is increased up to maximal tension during 2-3 seconds, the contractions were maintained for approximately 1 second. The torque value was measured by the loading point attached to the movement arm. Validity and reliability of measurement procedures and regulations are well established $[41,42]$. The measured torque values at any angle during the measurement and the re-measurement showed a very high reliability as of $r=0.63-0.96$ in patients with LBP [43], $r=0.94-0.98$ in patients without LBP [44]. Isometric lumbar extension torque values were measured at every 12 degrees up to the maximum lumbar extension ( 0 degree) from the maximum lumbar flexion (72 degree).

The subjects relaxed at between each measurement angle for about 10 seconds, while strength test was being conducted in each joint angle. All subjects were required to produce make maximum power at each angle. When the power was not maximum power, it was measured again $[42,45]$.

\section{Data analysis}

The IBM SPSS Statistics ver. 19.0 (IBM Co., Armonk, NY, USA) was used for statistical analysis. Results are presented as mean (standard deviation). The Shapiro-Wilk test
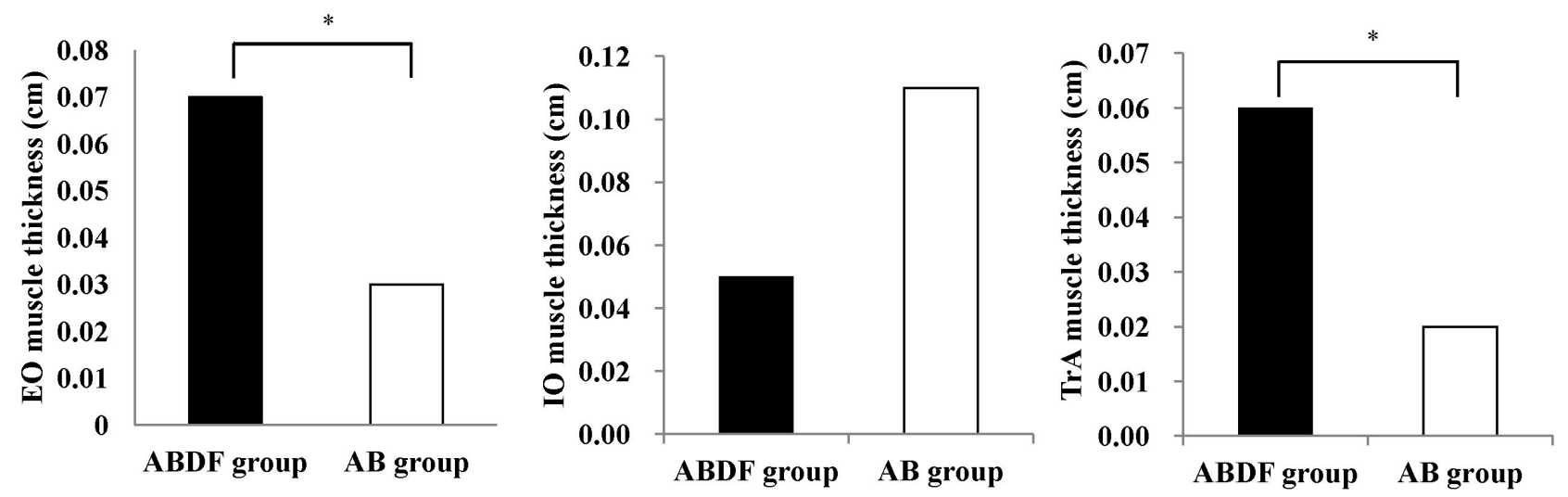

Figure 3. Differences of abdominal muscle thickness within and between abdominal bracing combined with ankle dorsiflexion (ABDF) group and abdominal bracing (AB) group. "Significant difference within and between both groups $(p<0.05)$. EO: external oblique, IO: internal oblique, TrA: transverse abdominis.
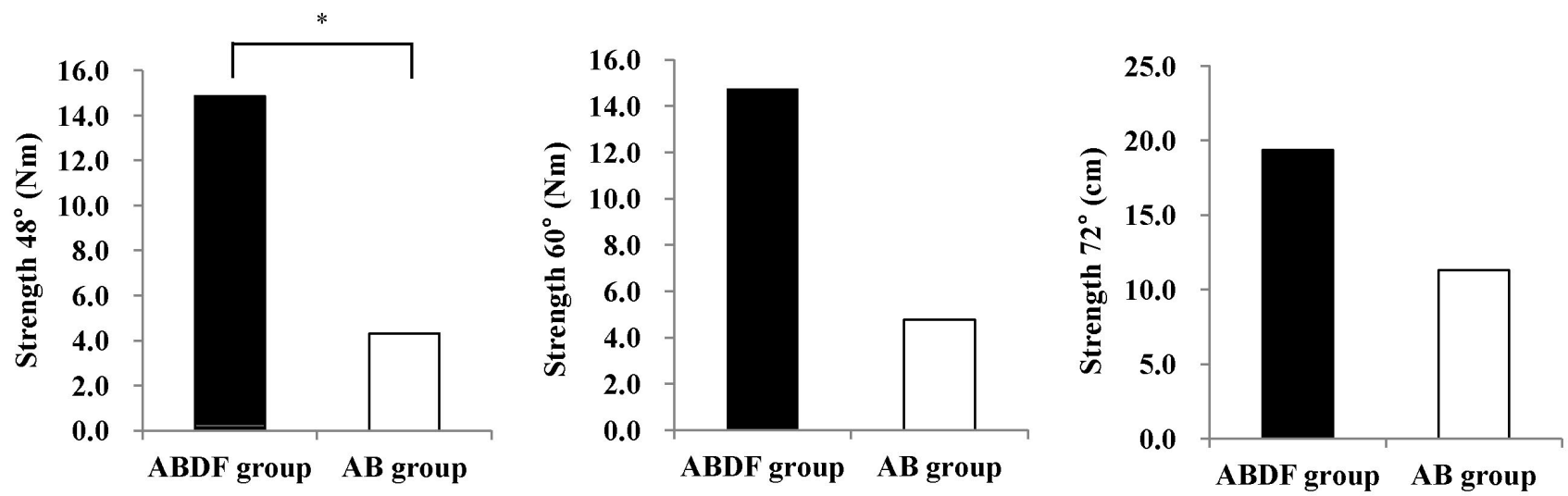

Figure 4. Differences of lumbar extensors strength within and between abdominal bracing combined with ankle dorsiflexion (ABDF) group and abdominal bracing (AB) group. * Significant difference within and between both groups $(p<0.05)$. MedX Medical Lumbar machine (MedX Inc., Ocala, FL, USA). 
was used to normalize the data. Chi-square analysis was used to calculate the frequency of difference for categorical variable (gender). The paired t-test was used to compare before and after of intervention within groups. The independent samples t-test was performed to investigate the significances of differences between groups. The significance level was set at 0.05 for all analyses.

\section{Results}

The general characteristics of the subjects were not significantly different between the ABDF group and AB group (Table 1).

For comparison within the group, the ABDF group showed significant improvement in EO, IO, TrA muscle thickness and strength values at $48^{\circ}, 60^{\circ}, 72^{\circ}$ for abdominal muscle strength, whereas the $\mathrm{AB}$ group showed only significant improvement the strength value at $48^{\circ}$ for abdominal $48^{\circ}$ abdominal muscle strength after intervention $(p<0.05$; Tables 2, 3; Figures 3, 4).

For comparison between the both groups, only EO and TrA muscle thickness and the strength value at 48 for abdominal $48^{\circ}$ abdominal muscle strength showed a significantly greater difference in the ABDF group than the $\mathrm{AB}$ group ( $p<0.05$; Tables 2, 3; Figures 3, 4).

\section{Discussion}

The aim of this study was to compare the efficacy of ABDF exercise and $A B$ exercise in the muscle thickness and strength of chronic LBP patients. Both exercises were effective in change of abdominal muscle thickness and muscle strength but the ABDF produced greater improvements in abdominal muscle thickness, and abdominal muscle strength in $\operatorname{MedX} 48^{\circ}$.

The important risk factor of LBP is weakness of superficial trunk and abdominal muscles, and strengthening of these muscles is often related to significant improvement of chronic LBP [46]. For this reason, various AB exercise studies with PBU have been conducted in an effort for improve muscle strength and motor control in persons with LBP. This study examined changes in abdominal muscle thickness using ultrasonography after 10 session of ABDF exercise in persons with LBP.

The abdominal muscle thickness after ABDF exercise was $0.06 \mathrm{~cm}$, a $12.8 \%$ (EO), $0.05 \mathrm{~cm}, 8.3 \%$ (IO), and 0.06 $\mathrm{cm}, 13.2 \%(\mathrm{TrA})$ improvement. Thus, the changes of ab- dominal muscle were found to be significantly improved by ABDF exercise. Also, the results of ABDF exercises demonstrated greater effectiveness as show by the EO and TrA muscle thickness changes than with $\mathrm{AB}$ exercises, which underwent only PBU exercises for the same duration.

Chon et al. [12] reported that the thickness of TrA was $0.24 \mathrm{~cm}$, which increased in ABDF exercise with ankle dorsiflexion compared to $\mathrm{AB}$ exercise without ankle action, and TrA and IO EMG peak amplitude was greater after the abdominal draw-in maneuver (ADIM) with ankle dorsiflexion was applied.

Hungerford et al. [47] reported that patients with lumbopelvic pain have been shown to have altered muscle recruitment patterns of the lateral abdominal muscles, which included the TrA, IO, and EO.

Kumar et al. [48] reported that the ADIM combined with core exercise for 5 weeks in patients with chronic LBP decreased visual analogue scale scores from 7 to 1, and Stuge et al. [49] demonstrated that the AB exercise combined isolated training was beneficial for painful and functional improvement in patients with LBP.

In the present study, in accord with a previous study, the ABDF exercise showed a treatment evidence to improve of abdominal muscle thickness and strength in patients with chronic LBP.

In this study, the abdominal strength of the ABDF group showed a significant increase after the intervention period at strength values at $48^{\circ}(p<0.05), 60^{\circ}(p<0.05)$, and $72^{\circ}$ $(p<0.05)$. In MedX training, trunk flexion had ABDF activated compared to trunk extension, especially EO [50]. Advanced ABDF thickness which provides stability on spines are capable of leading to adequate $\mathrm{AB}$ contraction against the trunk muscle.

The abdominal muscle is the leading muscle of expiratory. A recent study has monitored the activity of respiration related to ABDF. IO and TrA became much thicker during maximal expiratory action than single TrA action through ultrasonography as well as the EO in EMG [51].

This study proved that muscle contraction training of $\mathrm{AB}$ with ankle dorsiflexion was more effective for improving abdominal muscle activation and strength by increasing EO muscle, IO muscle and TrA muscle thickness in patients with chronic LBP.

There were some limitations to this study. First, due to a small sample size, it is difficult to make any generalizations. Second, there has not been considered the effects of respiration on changes in muscle thickness and muscle strength in 
the study. Therefore, further studies are warranted that will include all of the above considerations.

\section{Conflict of Interest}

The authors declared no potential conflicts of interest with respect to the authorship and/or publication of this article.

\section{References}

1. van Middelkoop M, Rubinstein SM, Verhagen AP, Ostelo RW, Koes BW, van Tulder MW. Exercise therapy for chronic nonspecific low-back pain. Best Pract Res Clin Rheumatol 2010;24:193-204.

2. Shin DC, Song CH. Realtionship of trunk muscle atrophy and provocation position in patients with chronic low back pain. Phys Ther Rehabil Sci 2012;1:28-32.

3. Tsao H, Tucker KJ, Hodges PW. Changes in excitability of corticomotor inputs to the trunk muscles during experimentally-induced acute low back pain. Neuroscience 2011;181:127-33.

4. Danneels LA, Coorevits PL, Cools AM, Vanderstraeten GG, Cambier DC, Witvrouw EE, et al. Differences in electromyographic activity in the multifidus muscle and the iliocostalis lumborum between healthy subjects and patients with sub-acute and chronic low back pain. Eur Spine J 2002;11:13-9.

5. Hodges PW, Richardson CA. Inefficient muscular stabilization of the lumbar spine associated with low back pain. A motor control evaluation of transversus abdominis. Spine (Phila Pa 1976) 1996;21:2640-50.

6. Arendt-Nielsen L, Graven-Nielsen T, Svarrer H, Svensson P. The influence of low back pain on muscle activity and coordination during gait: a clinical and experimental study. Pain 1996;64:231-40.

7. Hodges PW. Core stability exercise in chronic low back pain. Orthop Clin North Am 2003;34:245-54.

8. Zedka M, Prochazka A, Knight B, Gillard D, Gauthier M. Voluntary and reflex control of human back muscles during induced pain. J Physiol 1999;520 Pt 2:591-604.

9. May S, Johnson R. Stabilisation exercises for low back pain: a systematic review. Physiotherapy 2008;94:179-89.

10. Cresswell AG, Grundström H, Thorstensson A. Observations on intra-abdominal pressure and patterns of abdominal intra-muscular activity in man. Acta Physiol Scand 1992;144:409-18.

11. Sapsford RR, Hodges PW, Richardson CA, Cooper DH, Markwell SJ, Jull GA. Co-activation of the abdominal and pelvic floor muscles during voluntary exercises. Neurourol Urodyn 2001;20:31-42.

12. Chon SC, Chang KY, You JS. Effect of the abdominal draw-in manoeuvre in combination with ankle dorsiflexion in strengthening the transverse abdominal muscle in healthy young adults: a preliminary, randomised, controlled study. Physiotherapy 2010; 96:130-6.

13. Liebenson C, Karpowicz AM, Brown SH, Howarth SJ, McGill $\mathrm{SM}$. The active straight leg raise test and lumbar spine stability. PM R 2009;1:530-5.
14. Grenier SG, McGill SM. Quantification of lumbar stability by using 2 different abdominal activation strategies. Arch Phys Med Rehabil 2007;88:54-62.

15. Cholewicki J, McGill SM. Mechanical stability of the in vivo lumbar spine: implications for injury and chronic low back pain. Clin Biomech (Bristol, Avon) 1996;11:1-15.

16. Gardner-Morse MG, Stokes IA. The effects of abdominal muscle coactivation on lumbar spine stability. Spine (Phila Pa 1976) 1998;23:86-91; discussion 91-2.

17. Hodges PW, Richardson CA. Contraction of the abdominal muscles associated with movement of the lower limb. Phys Ther 1997;77:132-42; discussion 142-4.

18. Hodges PW, Moseley GL, Gabrielsson A, Gandevia SC. Experimental muscle pain changes feedforward postural responses of the trunk muscles. Exp Brain Res 2003;151:262-71.

19. Ferreira PH, Ferreira ML, Hodges PW. Changes in recruitment of the abdominal muscles in people with low back pain: ultrasound measurement of muscle activity. Spine (Phila Pa 1976) 2004; 29:2560-6.

20. Hides JA, Belavý DL, Cassar L, Williams M, Wilson SJ, Richardson CA. Altered response of the anterolateral abdominal muscles to simulated weight-bearing in subjects with low back pain. Eur Spine J 2009;18:410-8.

21. Dupeyron A, Demattei C, Koumdjian P, Missenard O, Micallef JP, Perrey S. Neuromuscular adaptations after a rehabilitation program in patients with chronic low back pain. BMC Musculoskeletal Disord 2013;14:277-86.

22. Lee SH, Kim TH, Lee BH. The effect of abdominal bracing in combination with low extremity movements on changes in thickness of abdominal muscles and lumbar strength for low back pain. J Phys Ther Sci 2014;26:157-60.

23. Hodges PW. Is there a role for transversus abdominis in lumbo-pelvic stability? Man Ther 1999;4:74-86.

24. Jull G, Richardson C, Toppenberg R, Comerford M, Bui B. Towards a measurement of active muscle control for lumbar stabilisation. Aust J Physiother 1993;39:187-93.

25. Chon SC, You JH, Saliba SA. Cocontraction of ankle dorsiflexors and transversus abdominis function in patients with low back pain. J Athl Train 2012;47:379-89.

26. Allison GT, Godfrey P, Robinson G. EMG signal amplitude assessment during abdominal bracing and hollowing. $\mathrm{J}$ Electromyogr Kinesiol 1998;8:51-7.

27. Lee SH, Kim TH, Lee BH. The effect of abdominal bracing in combination with low extremity movements on changes in thickness of abdominal muscles and lumbar strength for low back pain. J Phys Ther Sci 2014;26:157-60.

28. Lima PO, de Oliveira RR, de Moura Filho AG, Raposo MC, Costa LO, Laurentino GE. Reproducibility of the pressure biofeedback unit in measuring transversus abdominis muscle activity in patients with chronic nonspecific low back pain. J Bodyw Mov Ther 2012;16:251-7.

29. França FR, Burke TN, Caffaro RR, Ramos LA, Marques AP. Effects of muscular stretching and segmental stabilization on functional disability and pain in patients with chronic low back pain: a randomized, controlled trial. J Manipulative Physiol Ther 2012;35:279-85.

30. $\mathrm{Hu} \mathrm{H}$, Meijer OG, Hodges PW, Bruijn SM, Strijers RL, Nanayakkara PW, et al. Understanding the Active Straight Leg 
Raise (ASLR): an electromyographic study in healthy subjects. Man Ther 2012;17:531-7.

31. Costa LO, Maher CG, Latimer J, Smeets RJ. Reproducibility of rehabilitative ultrasound imaging for the measurement of abdominal muscle activity: a systematic review. Phys Ther 2009;89:756-69.

32. Hebert JJ, Koppenhaver SL, Parent EC, Fritz JM. A systematic review of the reliability of rehabilitative ultrasound imaging for the quantitative assessment of the abdominal and lumbar trunk muscles. Spine (Phila Pa 1976) 2009;34:E848-56.

33. McMeeken JM, Beith ID, Newham DJ, Milligan P, Critchley DJ. The relationship between EMG and change in thickness of transversus abdominis. Clin Biomech (Bristol, Avon) 2004;19:337-42.

34. Lee HJ, Shin KH, Jeong HS, Hong JS, Jeong SJ, Lee WH. The changes of rectus abdomonis muscle thickness according to the angle during active straight leg raise. Phys Ther Rehabil Sci 2013;2:44-8.

35. Hides J, Wilson S, Stanton W, McMahon S, Keto H, McMahon $\mathrm{K}$, et al. An MRI investigation into the function of the transversus abdominis muscle during "drawing-in" of the abdominal wall. Spine (Phila Pa 1976) 2006;31:E175-8.

36. Ainscough-Potts AM, Morrissey MC, Critchley D. The response of the transverse abdominis and internal oblique muscles to different postures. Man Ther 2006;11:54-60.

37. Critchley D. Instructing pelvic floor contraction facilitates transversus abdominis thickness increase during low-abdominal hollowing. Physiother Res Int 2002;7:65-75.

38. Henry SM, Westervelt KC. The use of real-time ultrasound feedback in teaching abdominal hollowing exercises to healthy subjects. J Orthop Sports Phys Ther 2005;35:338-45.

39. Arab AM, Chehrehrazi M. Ultrasound measurement of abdominal muscles activity during abdominal hollowing and bracing in women with and without stress urinary incontinence. Man Ther 2011;16:596-601.

40. Teyhen DS, Miltenberger CE, Deiters HM, Del Toro YM, Pulliam JN, Childs JD, et al. The use of ultrasound imaging of the abdominal drawing-in maneuver in subjects with low back pain. J Orthop Sports Phys Ther 2005;35:346-55.

41. Graves JE, Pollock ML, Foster D, Leggett SH, Carpenter DM,
Vuoso R, et al. Effect of training frequency and specificity on isometric lumbar extension strength. Spine (Phila Pa 1976) 1990; 15:504-9.

42. Graves JE, Webb DC, Pollock ML, Matkozich J, Leggett SH, Carpenter DM, et al. Pelvic stabilization during resistance training: its effect on the development of lumbar extension strength. Arch Phys Med Rehabil 1994;75:210-5.

43. Robinson ME, Greene AF, O'Connor P, Graves JE, MacMillan M. Reliability of lumbar isometric torque in patients with chronic low back pain. Phys Ther 1992;72:186-90.

44. Carpenter DM, Graves JE, Pollock ML, Leggett SH, Foster D, Holmes B, et al. Effect of 12 and 20 weeks of resistance training on lumbar extension torque production. Phys Ther 1991;71:580-8.

45. Fisher J, Bruce-Low S, Smith D. A randomized trial to consider the effect of Romanian deadlift exercise on the development of lumbar extension strength. Phys Ther Sport 2013;14:139-45.

46. Carpenter DM, Nelson BW. Low back strengthening for the prevention and treatment of low back pain. Med Sci Sports Exerc 1999;31:18-24.

47. Hungerford B, Gilleard W, Hodges P. Evidence of altered lumbopelvic muscle recruitment in the presence of sacroiliac joint pain. Spine (Phila Pa 1976) 2003;28:1593-600.

48. Kumar S, Sharma VP, Negi MP. Efficacy of dynamic muscular stabilization techniques (DMST) over conventional techniques in rehabilitation of chronic low back pain. J Strength Cond Res 2009;23:2651-9.

49. Stuge B, Veierød MB, Laerum E, Vøllestad N. The efficacy of a treatment program focusing on specific stabilizing exercises for pelvic girdle pain after pregnancy: a two-year follow-up of a randomized clinical trial. Spine (Phila Pa 1976) 2004;29:E197-203.

50. Stevens VK, Parlevliet TG, Coorevits PL, Mahieu NN, Bouche KG, Vanderstraeten GG, et al. The effect of increasing resistance on trunk muscle activity during extension and flexion exercises on training devices. J Electromyogr Kinesiol 2008;18:434-45.

51. Ishida H, Hirose R, Watanabe S. Comparison of changes in the contraction of the lateral abdominal muscles between the abdominal drawing-in maneuver and breathe held at the maximum expiratory level. Man Ther 2012;17:427-31. 